Western University

Scholarship@Western

Aboriginal Policy Research Consortium International (APRCi)

3-17-2011

\title{
Cultural Authenticity and Recovery Maintenance in a Rural First Nation Community
}

Aimee Nygaard

Follow this and additional works at: https://ir.lib.uwo.ca/aprci

Part of the Substance Abuse and Addiction Commons

Citation of this paper:

Nygaard, Aimee, "Cultural Authenticity and Recovery Maintenance in a Rural First Nation Community" (2011). Aboriginal Policy

Research Consortium International (APRCi). 249.

https://ir.lib.uwo.ca/aprci/249 


\title{
Cultural Authenticity and Recovery Maintenance in a Rural First Nation Community
}

\author{
Aimee Nygaard \\ Published online: 17 March 2011 \\ (C) Springer Science+Business Media, LLC 2011
}

\begin{abstract}
This study explored a rural, First Nation understanding of factors, particularly the role of culture, supporting recovery maintenance from problem substance use. A crosssectional, qualitative research design and community-based methodology were used. Participants included 20 members of a rural Canadian community self-identifying as recovering, or recovered, problem substance users, and those with professional experience with First Nations recovery. Semi-structured, open-ended interviews gathered in-depth accounts of the recovery experience examined through a thematic analysis. Culture emerged as a contested concept, and was viewed along a spectrum from detrimental, to somewhat helpful to very beneficial in the recovery process. Community change emerged as a key theme. Conclusions suggest that the tension in understandings of culture in this context inhibit potential social supports for recovery. However, whatever power culture may hold, socio-economic context is also a significant factor that must be addressed to support long term recovery.
\end{abstract}

Keywords Cultural healing · First Nations · Socio-economic disadvantage · Alcoholism · Recovery maintenance $\cdot$ Rural communities

In North America, cultural healing has become the preferred style of treatment for many indigenous people with alcohol problems. There is a broad range of research in Canada and abroad documenting individual and community empowerment due to culturally based healing programs and treatment centers (Spicer 2001; Dell and Lyons 2007; Prussing 2008; Mohatt et al. 2007; Acoose and Dell 2009; Wesley-Esquimaux and Snowball 2010). Yet, shifting the focus from treatment centers and cultural healing programs we find much less

A. Nygaard
Department of Sociology, The University of Toronto, Toronto, Canada

A. Nygaard $(\bowtie)$

ACT, 16 Garling Street, Lyneham, Australia 2602

aimee.nygaard@anu.edu.au 
research on how culture intersects with alcoholism recovery in the home environment, or how those in a rural setting manage to maintain sobriety without treatment or urban resources. The growing popularity of the idea that "culture is treatment" implies that everyday cultural experiences can act as an important source of healing in communities (Green 2010). There is also ongoing debate as to what exactly constitutes the authentic cultural experience meant to support recovery from alcohol use (Brady 1995; Spicer 2001; Torres Stone et al. 2006; Green 2010). In response to these gaps this paper will explore a rural perspective of the role played by First Nations culture in recovery from alcoholism, with the intent being to understand not only how culture may bolster resilience, but also what constitutes "cultural authenticity" for both indigenous and non-indigenous residents of a remote community.

This focus on recovery and the role of culture is spurred by the ongoing devastation caused by substance abuse in indigenous communities in Canada and worldwide (de Leeuw et al. 2010; Waldrum et al. 2008; Chansonneuve 2007). For example, in British Columbia status First Nations are more than six times as likely as the general population to suffer alcohol related deaths, with an alcohol related mortality rate of $23.5 \%$ (Aboriginal Health Services 2006). While many communities and individuals are free of substance abuse problems, the concentration of trauma and disorder that persist in others warrants consideration.

The research for this project was carried out in a coastal community in British Columbia with a mixed First Nation and general population. The majority of the First Nation population lives on a reserve characterized by poverty and social dysfunction as well as rich cultural traditions, including ceremonies, dancing, artwork, language and food production. Although no exact numbers exist, local estimates indicate that alcoholism is a major problem on the reserve, as are unemployment and crime. This mixed community setting goes beyond the typical focus on treatment program outcomes and offers an opportunity to understand the perceptions and lived experience of those immersed in a culturally vital but alcohol dependant community.

\section{Cultural Destruction and Healing}

In the literature, there is general agreement that the cultural devastation of indigenous peoples has resulted in a variety of negative individual, family and community impacts, which in turn promote destructive patterns of substance abuse (Prussing 2008; Green 2010; Lavallée and Poole 2010). Some researchers make the direct link that "for many Aboriginal people, consumption of alcohol has been their attempt to deal with the state of powerlessness and hopelessness that has arisen due to the devastation of traditional cultural values" (McCormick 2000: 27). This is the argument used to validate culturally based treatment practices and programs, such as the innovative research carried out by Dell and her colleagues with female indigenous offenders (Dell and Lyons 2007; Acoose and Dell 2009). Cultural understanding emerged as central to building a healthy sense of self for women struggling with substance abuse and criminal problems. Gaining an awareness of historical roots from their culturally based treatment allowed women to put features of their own lives into perspective, move past self-blame, and establish a positive self-identity. Healing in the aboriginal context is seen as encompassing not only typical concerns such as peer support and overcoming personal challenges, but also the need to address broader socio-political issues such as the impacts of colonization and residential school on identity (Lavalee and Poole 2010). 
Culture as Fluid and Heterogeneous

However, the "culture is treatment" picture is complicated by arguments that aspects of indigenous cultures can actually foster substance abuse and prevent sobriety. Brady (1995) argues that while aboriginal culture can be an important part of healing from addiction, there are often elements of traditional cultures that promote drinking in aboriginal communities. Her evidence is the prevalence of problematic drinking in communities that have never been dispossessed from their land and maintain their language and strong cultural traditions. In her view, a lack of appropriate social support renders potentially beneficial cultural values irrelevant. Spicer (2001) contends however that in his research, drinking, while perhaps commonplace, is viewed as external to traditional Indian culture, being more of a manifestation of "cultural degradation and loss" (232). White (2008) would probably advise that there are cultures of both addiction and recovery operating within broader social milieus, which brings us to the realization that culture itself is a nebulous concept subject to interpretation. For instance, the tension between the pan-Aboriginal cultural identity often utilized in culturally based healing and the much more complex lived realities of people leads Kirmayer et al. (2003) to offer that "like all cultural identities, Aboriginality is not 'in the blood' but rooted in forms of life that exist at the confluence of historical currents and contemporary forces" (19). From within this fluid and heterogeneous conceptualization of culture one can appreciate the diversity of indigenous cultures, as well as the diversity of individual interpretation of what culture means. One of the aims of this study is to clarify what views of culture predominate in this rural setting, and how different views may relate to addiction and recovery.

\section{Purpose}

The data presented here were collected to fulfill requirements for the researchers' Masters in Arts (Sociology) research paper at the University of Toronto in 2010. This project was an exploratory study to identify what role culture was perceived to play for First Nations people in recovery from alcoholism, as such, the data is limited to the views of participants rather than being verifiable claims about recovery maintenance itself. This general aim was accomplished by identifying how participants felt recovery from problem drinking was experienced, and possibly shaped by culture in a rural First Nations context.

Research Question What role do participants feel culture plays in maintaining recovery for themselves and/or other First Nations people with alcohol problems?

\section{Methods}

Sample and Recruitment

Participants were individuals from the reserve who self identified as recovered problem drinkers, and First Nation elders, treatment providers and experts, as well as local police, health, education and social service authorities. The intention was to access key informants from both indigenous and non-indigenous populations with expertise on alcoholism and recovery, and all views were taken into account. Twenty in-depth, 
audio-recorded interviews were held with 11 women and nine men; 13 from the First Nation community and the remaining seven from the general population. The average time abstinent was 14 years, with a range of 18 months to 25 years, and only four had participated in formal treatment programs amongst the 10 recovering First Nation participants.

The researcher had pre-existing contacts in the community used over the course of a 6 week residence to conduct word of mouth, snowball sampling recruitment (Maxwell 2005). Snowball sampling is especially useful for accessing noninstitutionalized hidden populations, such as recovering alcoholics in this case (Salganik and Heckathorn 2004). Initial gatekeepers, one involved in First Nations youth work and one a long time resident, provided knowledge of key organizations and programs and provided introductions to an initial list of nine individuals. In a small community where "everyone knows everyone" the "seed" participants were able to provide contacts they felt would provide a diversity of views. Participants were asked to provide the researchers' contact details to others who might be interested in being in the study. The remaining 11 participants were recruited in this way or by the researcher directly as she became better acquainted with the community. It was felt that given the cultural background difference between researcher and participants, the risk of sampling bias from this recruitment strategy was balanced by the trust conferred through introductions (Babbie 2004).

\section{Data Collection}

The potential vulnerability of the research sample, as being former alcoholics as well as First Nations, required the researcher to follow stringent ethical procedures outlined in an approved University of Toronto Ethics Review Protocol. A "relational methodology" was used, wherein researchers attempt to collaborate with communities to build responsible relationships and "share results that have practical value" (Trimble 2008: 381, see also Smith 1999). Consequently, findings were verified by representative participants, who were given a chance to comment and provide clarification on an early draft of the study. Also, a copy of the original report was made available to participants and relevant organizations. Recruitment relied on volunteerism and there was no compensation, people had no incentive other than personal interest to participate.

Contact was made with potential interviewees by phone and if they agreed to meet a time and date was scheduled at a location identified by the individual. Informed consent was obtained in verbal and written format prior to interviews. The consent form provided details of research objectives, a guarantee of anonymity, and of their right to withdraw participation at any time. It was stressed that this research would not implicate the identity of participants or their community. As a result, all names of people and places have been changed in this report, and the details of people's lives have been minimally presented. Interviews were audio-recorded and lasted an average of $45 \mathrm{~min}$ to $1 \mathrm{~h}$, and field notes and transcripts were typed up immediately after interviews.

Interview design was based on an open-ended, semi-structured format to elicit relevant cultural and relational information about how participants viewed the recovery process. This kind of format has been shown in the literature to be particularly well suited to addressing personal meanings and beliefs involved with addiction recovery (Mohatt et al. 2007; Spicer 2001). The study carried out by Mohatt et al. (2007) provided the methodological template for this study, as they also were seeking the perspectives of Aboriginal people about recovery. In this study, it is this final stage of recovery 
maintenance that is the focus, as it is from within this stage that individuals would be trying to maintain sobriety in their daily life without institutional support (White 2008). A three part interview protocol was used to encourage participants to share thoughts and feelings about how they had experienced, or witnessed, recovery from problem drinking. There was a specific focus on: what factors were felt to be most important in recovery and the maintenance of sobriety; what culture meant in their own lives; and, what they felt the role of culture to be in recovery. Community change emerged as an important issue, and probes were included to examine this following the seventh interview.

\section{Analysis}

Audio-recordings were transcribed in full and analyses conducted by the primary researcher. The thematic analyses used involved memo writing and open coding based on the theme of 'culture as healing' generated from prior research. It was felt that this mid level analyses (as opposed to theoretically or data based coding) would maintain sensitivity to the local context as well as relevance to broader issues (Boyatzis 1998). The researcher analyzed the data through the three steps described in Boyatzis' (1998) guideline to thematic analyses. First, transcripts were reviewed and codes generated that aligned with participant views of how culture was felt to interact with recovery. A defining feature that emerged was strong variation in how culture was viewed, resulting in three broad categories of views being presented. Secondly, these three categories were reviewed in context of the data, and secondary themes drawn out. Each interview was reread and summarized to allow context to be maintained for quotes used in the presentation of results, and the quotes related to each theme were cut and pasted into separate documents so that similarities and differences between the participant's perspectives could be appreciated (Maxwell 2005).

The third step of determining reliability involved acknowledging potential preconceived notions and biases given the solitary analyses. Some methods of verification used to enhance credibility of the findings included researcher engagement in community social life and events for a period of 6 weeks and mamboing of narratives before coding was carried out. Given the risk of reduced reliability because of only one researcher analyzing data, findings were verified with representatives from both indigenous and non-indigenous participants. Also, triangulation across organizations and data sources such as First Nation and government websites, community resource documents, and academic literature helped to validate that findings were relevant (Maxwell 2005). Verification of findings with participants was particularly beneficial, as insightful feedback was provided on several issues by participants.

\section{Findings}

\section{Overview of Findings}

The role of culture in recovery was contested and ranged along a spectrum from being viewed as a liability, to moderately useful through to being strongly preventative. Within these three views there were distinct understandings of what culture actually is, as well as its relevance in maintaining recovery. Inextricably connected to the idea of culture in recovery were issues related to community change, historical and current. 
The Role of Culture in Recovery

\section{Culture as Liability}

There were several participants, from both ethnic groups, who felt that culture was actually a liability for recovering alcoholics. Granted, those making this claim had not personally experienced culturally based treatment; however, the selection criteria ensured that all had significant experience with indigenous alcoholism and recovery in some respect. One of the most vehement rebuttals of the positive impact of culture on recovery came from an older, non-indigenous male with long experience in AA:

...if they used to have a very broad culture it was destroyed a long long time ago. It's a dangerous thing to bring in somebody else's culture... As far as I can tell, their culture, the natives here, cultural development inhibits and stops personal differentiation.

This participant identifies two points that several other non-aboriginal participants also mention, although none in such provocative terms. One, that it is somehow detrimental to bring in the cultural features of other aboriginal groups for healing, and two, that certain social aspects of the local aboriginal culture are actually conducive to alcohol abuse. This latter point was also repeated by those who held more positive views on culture. Another non-indigenous woman in the community, also with many years experience with AA, provided this example:

I know they have a harder time of it, because their lifestyle is very open. I had one lady...she was just hangin' on by the skin of her teeth to keep from drinking, and she had two friends, or acquaintances, drinkers, who just come into her house and threw two bottles in her lap. How do you fight something like that? See, and white people are kind of selfish that way, we're going to keep the booze for ourselves.

This example expresses a commonly held view that the openness and generosity of the local culture can foster norms conducive to a strong drinking culture.

One feature of this group of accounts was the view of culture as something based on particular activities. An older woman from the Reserve felt that there was nothing in their culture that really contributed to healing, saying:

if sweats were a part of our culture, maybe that would help, but sweats aren't really a part of our culture...no I don't see how the culture helps people that are alcoholics.

The pessimistic view of her own culture reflects this woman's experience of being heavily involved in cultural activities with her family, as well as seeing many family members succumb to alcoholism despite their engagement in cultural activities. This is perhaps not a surprising result given the rich cultural heritage of the community as well as the prolific use of alcohol.

\section{Culture as Useful}

Another perception among participants was that culture has an important role to play, but is only one aspect of other equally important issues. This was the view put forward by a First Nation official, who stated about culture:

Yeah, it can help, but you need other factors to help out of course...I think that's why there's so many problems is the loss of culture, and the people are kind of lost in a 
way. Its hard to get out of that rut of not having it [culture] and trying to incorporate it back in. It's getting there I think.

He went on to suggest that economic issues were also a major factor contributing to local alcoholism, and expressed optimism about the impact of future economic developments in the community on general well being, discussed further in Community Change.

In several cases, individuals drew upon one particular aspect of their culture, which became significant to their recovery. These could include the observation of cultural dances and singing, creating cultural artifacts, involvement in language and cultural teaching, and in one case, a powerful, transformative experience with an aboriginal spiritual healer. One woman from the reserve expressed mixed feelings about her cultural identity, having experienced early sexual abuse and both gambling and alcohol addictions. She stated that despite occasional feelings of anger with her First Nation identity: "when I'm out I say I'm-Nation, I'm proud of who I am. Yeah I feel it's really important, and it's good to have that as a part of your healing, definitely." For her, and several others, recovery maintenance required active identity work through repeated treatment and counseling episodes and lifestyle change. The implication from the stories of this group of recovering participants was that a positive cultural identity emerged, or re-emerged, as healing progressed, and then this revitalized sense of cultural connectedness acted as an additional source of support in recovery.

\section{Culture as Preventative}

There were also participants who felt that having a strong cultural identity bolstered personal resilience, preventing relapse. The greatest proponents of this view were typically those involved in providing cultural treatment, typically having first experienced treatments themselves. There was the sense that engagement in cultural activities in conjunction with awakening of cultural identity and spirituality could be brought about though participation in the local cultural healing camps. Those involved in these camps argue that their programs allow people to get healthy, and get in touch with others through an emphasis on respectful teamwork, spiritual awareness, artistic expression and getting to know the land. An experienced indigenous counselor described that during the wilderness camps, individuals:

transform themselves through various cultural activities that are outlined for them.

For example, purification, sweat lodge, mask, song, and dance, earth, wind and fire, traditional food gathering, medicine gathering, canoe journeys.

There was the sense that these camps provide a very powerful learning experience, and are often the first time individuals gain positive knowledge of their culture or engage with personal issues of trauma and healing. It was expressed by this counselor that understanding and living by the four key cultural beliefs "really helps people with their pride and self esteem, and just respect for other people." These beliefs include: "Never say or do hurtful things to one another; Share a meal together or feast; Never take your life or of another; Love creator and yourself." These traditional teachings had been drawn from the local aboriginal culture; however, some aspects of cultural healing were drawn from other aboriginal or mainstream cultures. As mentioned earlier, incorporating external cultural practices such as a sweat lodge, or sweat grass ceremony, was sometimes viewed negatively, but as one non-aboriginal participant offers, "well, if it works, then why not?" This was also the attitude of those in this category, who augmented core local cultural beliefs with beneficial external practices. 
Destructive social elements were viewed as external to traditional and non-traditional beliefs and values recognized for their role in healing. For participants engaged in the recovery process drinking was seen as incompatible with the teachings of elders. One middle-aged woman described, "the cultural stuff it never ever left, it was just put on the back burner because of alcohol." As a child this woman had been taught traditional dancing and healing by her grandmother, but lost these ways during many years of severe alcohol abuse marked by extremely violent relationships with men. Emerging from her destructive patterns into a healthy life, she regained an interest in traditional practices. She expressed that the healing path had inspired her to pass her traditional knowledge on to her own children, to help them in their struggles. Others felt the cultural teachings could play a preventative role in youth problem drinking (and suicide) by providing a stronger sense of self-identity and self-worth. Overall, the sense was that traditional cultural values and beliefs, as well as external healing practices, could reinforce a positive cultural identity beneficial to recovery maintenance.

\section{Community Changes: Dealing with the Past, Planning for the Future}

A key theme to emerge from nearly every account was the need for community level changes to engender a more supportive environment for those trying to stay sober. As current problems were typically viewed as a result of residential school, many advocated for greater community wide recognition of the generational impacts of sexual, physical and emotional abuse. A middle-aged, indigenous man describes the impacts of residential schooling on his own family:

My grandmother was sent to residential school, where they weren't allowed to speak their language, they came through all that part where the potlatch was abolished, you couldn't do the dances, the regalia was all taken away...And their resentments and anger from the past is passed down to their children, from their children to us.

Breaking this generational cycle of dysfunction was seen to require increased community responsibility, as one middle-aged woman states: "We just need to pull together as a community... And the longer we are the way we are now, the longer our kids will keep doing what they're doing." However, there was some pessimism about trying to make changes. A female elder confided that the elders would like nothing more than to clean the community out of drugs and alcohol but there was a well-grounded fear about repercussions, this highlights how entrenched a drinking culture is in the community.

On the practical side, it was noted by nearly everyone that more things should be available to keep people occupied, such as family and youth programming and facilities. Economic factors were also cited as a key area of community change that could be beneficial for those trying to recover. A First Nation official noted that: "[People] need a reason to get up in the morning and have something to do, and feel good about themselves for accomplishing something." In a related vein, funding came up time and again as a factor preventing adequate support for alcoholics in particular and the community in general. One elder stated about cultural healing programs that "the government doesn't fund those things, because it's traditional... these camps are empowering people. They don't like to see any aboriginal peoples have power". There was a strong desire to provide community follow up for those who had gone out to cultural treatment camps, but inability to do so because of the lack of funding. In general, there was the feeling that significant community level issues contributed to the entrenched nature of alcoholism on the reserve. However, there was also 
a sense of optimism amongst several participants. An RCMP officer mentioned that "change is in the air...things seem to be getting better", as new programs are being implemented that bring groups together; some youth are turning from alcohol to careers in traditional art; and culture and traditional ways are reinvigorated as youth are taught about the Four Laws and other cultural traditions in school.

\section{Discussion}

The findings indicate that culture in this rural context is indeed subject to multiple interpretations, and passionately so, as often there was little acknowledgement of alternate perspectives. The sometimes ambivalent, or conflicting, feelings towards culture from within this sample offers insights of relevance to similar communities.

\section{Culture as Contested}

The role of culture in recovery is contested, in the sense that different views were held on what culture means, and whether it can act as a support in recovery. Those who identified aboriginal culture only as the interpersonal relations between people, or as the tangible expression in dance, singing and art, were likely to view it as a liability or unimportant in recovery, or as overwhelmed by the powerful influence of the local drinking culture. These were often non-aboriginal participants and a few aboriginal participants without first hand experience of cultural treatment. The negative impressions of cultures role in recovery related back to what Brady (1995) had cautioned, that cultural identification can be negated by a lack of non-drinking support and that there may be aspects of the aboriginal culture itself that promote drinking.

It seemed to be difficult for some participants to view aboriginal culture as adaptable and subject to interpretation and change. Those who struggled with the idea of aboriginal culture being a positive influence typically did not recognize the significance of traditional beliefs and values. Yet, it was these teachings that were viewed as fundamentally important to those in recovery in (re-)building a positive self-identity. The prevalence of this rigid interpretation of culture suggests that while the pan-aboriginal healing movement may be informing treatment programming, First Nation people have to surmount the additional hurdle of cultural disregard within their own communities. Promoting a more widespread understanding of the positive role played by local cultural beliefs and values could build community relations and support for recovering alcoholics.

\section{Cultural Identity and Resilience}

Although this sample was by no means representative, there was a strong indication from some First Nation participants that cultural identity was an important factor in maintaining long term recovery. Here, culture was seen as constituting an important part of a healthy, positive self-identity through adherence to traditional values, as one might expect given the literature on the topic (Spicer 2001; Kirmayer et al. 2003; Dell and Lyons 2009). Profound personal transformations were typically acknowledged as accompanying prolonged abstinence, and often a renewed sense of cultural identity and involvement arose as participants sought out a more balanced life. Lavalee and Poole (2010) offer that "treating the symptoms of ill health, including addiction and mental health is a band-aid solution that does not treat the root causes - colonization and identity disruption" (275). It is perhaps 
unsurprising that traditional values and activities were turned to as a source of direction. But while not surprising, it does vindicate again the importance of resolving both individual and collective identity issues for indigenous peoples struggling with addiction.

\section{Structural Factors}

There was awareness that community level change could impact recovery for residents, in line with calls for more holistic treatment protocols (White 2008; Laudet 2007; Pridemore 2005). Sexual abuse emerged as a community level concern, and the impressions of some participants, that the extent of sexual abuse and its impacts must be publicly acknowledged, is similar to other First Nations working towards community healing (Lane et al. 2002). References to the damaging impacts of poverty reinforce the significance of meaningful employment in the lives of recovering individuals and stable funding for community initiatives. Additionally, there is no escaping the fundamental need to address cultural and social losses incurred by residential school, and the interconnectivity between historical socio-cultural disruptions and their generational impacts. As de Leeuw et al. (2010) contends, "we insist on understanding unhealthy families and communities as socially and historically determined" (291). Those participants involved in providing treatment for their people in this study were quite aware of the historical and current structural determinants of their present difficulties. They were equally aware that effectively mitigating these social and economic factors requires resources on a level beyond what is presently available.

\section{Limitations}

This is an exploratory study, of value for the depth of meaning extracted from in-depth interviews in a difficult to reach population. The findings may not be generalizable to the broader public given the relatively small number of participants. Also, the views provided by the participants cannot be thought of as representative of all First Nation or aboriginal communities given the diversity of aboriginal cultures (Blue and Darou 2005). However, similarities in circumstances of colonization and current psycho-social functioning suggest that the experiences in one location might have relevance in other communities (McCabe 2007). The lessons and insight drawn from this work may guide future research; as well as support policy and programs in similar settings.

\section{Conclusion}

The contested notions held about cultural authenticity was a powerful undercurrent in the narratives presented here. In its most beneficial form of promoting positive identity transformation, culture was characterized as being embedded with the best wisdom of both past and present. However, it was also apparent that the potentially powerful, positive influence of cultural identification was seen as inhibited by the burden of generational family dysfunction and current economic hardship. It can be argued then that cultural identification in this context was perceived to be a beneficial resource when a deeper understanding of culture was expressed, while more superficial perspectives led to more ambivalent expectations in recovery. The most surprising finding to emerge from this study was how fervently some participants felt about the role of culture in recovery, and how diametrically opposed these views often were. There is a need to build mutual understanding and support within such communities by addressing conflicting notions of 
cultural authenticity. This research highlights the reality that the effects of colonialism are so multidimensional that culture is only one part of the puzzle- and solutions to address issues like addiction must also address a broad range of interconnected structural problems like economic development, racism, access to resources, health and education. Neglecting a multidimensional approach will only perpetrate the generational cycle of disadvantage and addiction in some First Nations communities and undermine the beneficial qualities of cultural identification.

Implications of this study for future research include a greater focus on the role of artistic expression and employment among recovering aboriginal individuals. Research into the impact of economic revitalization on addiction in the aboriginal context could also provide valuable insight, especially seeing as meaningful employment may be especially helpful for recovering alcoholics in isolated areas.

Conflicts of Interest The primary researcher has no financial relationship with the organization that sponsored this research, and has full control of all primary data, which the journal may review if requested.

\section{References}

Aboriginal Health Services. (2006). Aboriginal Health Plan 2007-2010. Fraser Health. Retrieved 10/03/2011 from: <http://www.fraserhealth.ca/media/Aboriginal $\% 20 \mathrm{Health} \% 20 \mathrm{Plan} . p d f>$.

Acoose, S., \& Dell, C. A. (2009). Hear me heal: First Nations women healing from drug abuse. In: R. W. Herbe (Ed.), Indigenous education: Pacific Nations Saskatchewan: First Nations University of Canada. pp. $1-8$.

Babbie, E. (2004). The logic of sampling. In E. Howard (Ed.), The practice of social research (10th ed., p. 184). Belmont: Wadsworth/Thomson.

Blue, A., \& Darou, W. (2005). Counselling First Nations People, In Culture- infused counselling: Celebrating the Canadian mosaic. Calgary, AB: Counselling Concepts. pp. 3-296.

Boyatzis, R. E. (1998). Transforming qualitative information: Thematic analysis and code development. Thousand Oaks: Sage.

Brady, M. (1995). Indigenous residential treatment programs for drug and alcohol problems: Current status and options for improvement? Discussion Paper \#236. Australia National University: Center for Aboriginal Economic Policy Research.

Chansonneuve, D. (2007). Addictive behaviours among aboriginal people in Canada. Ottawa: Aboriginal Healing Foundation.

de Leeuw, S., Greenwood, M., \& Cameron, E. (2010). Deviant constructions: how governments preserve colonial narratives of addictions and poor mental health to intervene into the lives of Indigenous children and families in Canada. International Journal of Mental Health and Addiction, 8, 282-295.

Dell, C., \& Lyons, T. (2007). Harm reduction policies and programs for persons of aboriginal descent. Ottawa: Canadian Centre on Substance Abuse.

Dell, C., \& Lyons, T. (2009). Aboriginal women drug users in conflict with the law: A study of the role of selfidentity in the healing process. Cedar Lodge Event Center, Feb.15, 16 and 17, 2009. Saskatchewan: University of Saskatchewan. Retrieved 12/06/10 from: <http://www.addictionresearchchair.com/wpcontent/ uploads/CedarLodgeReport.FINAL.2009- publications-page.pdf $>$.

Green, B. (2010). Culture is treatment: considering pedagogy in the care of aboriginal people. Journal of Psychosocial Nursing, 48(7), 27-34.

Kirmayer, L., Simpson, C., \& Cargo, M. (2003). Healing tradition: culture, community and mental health promotion with Canadian aboriginal peoples. Australasian Psychiatry, 11, 15-23.

Lane, P., Bopp, M., Bopp, J., \& Norris, J. (2002). Mapping the healing journey: The final report of a first nation research project on healing in canadian aboriginal communities. Ottawa, ON: Solicitor General of Canada, Aboriginal Corrections Policy Unit. 
Laudet, A. B. (2007). What does recovery mean to you? Lessons from the recovery experience for research and practice. Journal of Substance Abuse Treatment, 33, 243-256.

Lavallée, L. F., \& Poole, J. M. (2010). Beyond recovery: colonization, health and healing for indigenous people in Canada. International Journal of Mental Health and Addiction, 8, 271-281.

Maxwell, J. (2005). Qualitative research design: an interactive approach. Applied social research methods series, volume 41 (2nd ed.). Thousand Oaks: Sage.

McCabe, G. H. (2007). The healing path: a culture and community-derived indigenous therapy model. Pyschotherapy: Theory, Research, Practice, Training, 44(2), 148-160.

McCormick, R. M. (2000). Aboriginal traditions in the treatment of substance abuse. Canadian Journal of Counseling, 34(1), 25-32.

Mohatt, G. V., Rasmus, S., Thomas, L., Hazel, K., \& Marlatt, G. A. (2007). Risk, resilience, and natural recovery: A model of recovery from alcohol abuse for Alaska Natives. Addiction, 103, 205-215.

Pridemore, W. A. (2005). A culturally informed developmental approach to understanding risk and resiliency among native american youth. Journal of Ethnicity in Criminal Justice, 3(1), 111-129.

Prussing, E. (2008). Sobriety and its cultural politics: an ethnographer's perspective on "Culturally Appropriate" addiction services in native North America. Ethos, 36(3), 354-375.

Salganik, M. J. \& Heckathorn, D. D. (2004). Sampling and estimation in hidden populations using respondent-driven sampling. Sociological Methodology, 34, 193-239.

Smith, L. T. (1999). Decolonizing methodologies: Research and indigenous peoples. London: Zed Books.

Spicer, P. (2001). Culture and the restoration of self among former American Indian drinkers. Social Science \& Medicine, 52, 227-240.

Torres Stone, R. A., Whitbeck, L. B., Chen, X., Johnson, K., \& Olson, D. (2006). Traditional practices, traditional spirituality, and alcohol cessation among American Indians. Journal of Studies on Alcohol, 67, 236-244.

Trimble, J. E. (2008). Commentary: no itinerant researchers tolerated: principled and ethical perspectives and research with North American Indian communities. Ethos, 36(3), 380-383.

Waldrum, J. B., Herring, D. A., \& Young, T. K. (2008). Aboriginal Health in Canada: Historical, cultural and epidemiological perspectives. Toronto: University of Toronto Press.

Wesley-Esquimaux, C., \& Snowball, A. (2010). Viewing violence, mental illness and addiction through a wise practices lens. International Journal of Mental Health and Addiction, 8(2), 390-407.

White, W. (2008). Recovery management and recovery-oriented systems of care: Scientific rationale and promising practices. Pittsburgh, PA: Northeast Addiction Technology Transfer Center, Great Lakes Addiction Technology Transfer Center, Philadelphia Department of Behavioral Health and Mental Retardation Services. 